\title{
Mechanical characterization of pore-graded bioactive glass scaffolds produced by robocasting
}

https://doi.org/10.1515/bglass-2019-0012

Received Jul 29, 2019; revised Nov 17, 2019; accepted Nov 17, 2019

Abstract: Since the discovery of $45 \mathrm{~S} 5$ Bioglass ${ }^{\circledR}$ by Larry Hench, bioactive glasses have been widely studied as bone substitute materials and, in more recent years, have also shown great promise for producing three-dimensional scaffolds. The development of additive manufacturing techniques and their application in bone tissue engineering allows the design and fabrication of complex structures with controlled porosity. However, achieving strong and mechanically-reliable bioactive glass scaffolds is still a great challenge. Furthermore, there is a relative paucity of studies reporting an exhaustive assessment of other mechanical properties than compressive strength of glassderived scaffolds. This research work aimed at determining key mechanical properties of silicate $\mathrm{SiO}_{2}-\mathrm{Na}_{2} \mathrm{O}-\mathrm{K}_{2} \mathrm{O}$ $\mathrm{MgO}-\mathrm{CaO}-\mathrm{P}_{2} \mathrm{O}_{5}$ glass scaffolds fabricated by robocasting and exhibiting a porosity gradient. When tested in compression, these scaffolds had a strength of $6 \mathrm{MPa}$, a Young's modulus around $340 \mathrm{MPa}$, a fracture energy of $93 \mathrm{~kJ} / \mathrm{m}^{3}$ and a Weibull modulus of 3, which provides a quantification of the scaffold reliability and reproducibility. Robocasting was a suitable manufacturing method to obtain structures with favorable porosity and mechanical properties comparable to those of the human cancellous bone, which is fundamental regarding osteointegration of bone implants.

Keywords: Bioactive glass, Scaffold; Robocasting; Mechanical properties

\footnotetext{
^Corresponding Author: Francesco Baino: Institute of Materials Physics and Engineering, Department of Applied Science and Technology, Politecnico di Torino, Turin, Italy;

Email: francesco.baino@polito.it

Jacopo Barberi, Elisa Fiume, Enrica Verné: Institute of Materials Physics and Engineering, Department of Applied Science and Technology, Politecnico di Torino, Turin, Italy

Amy Nommeots-Nomm: Department of Mining and Materials Engineering, McGill University, Montreal, Canada Jonathan Massera: Faculty of Medicine and Health Technology, Tampere University, Tampere, Finland
}

\section{Introduction}

Making strong bioactive glass scaffolds with suitable pore features for promoting bone repair and regeneration in load-bearing osseous segments is still a challenge in biomaterials science. The fabrication of three-dimensional (3D) porous bioactive glass scaffolds was independently pioneered in 2006 by Park et al. [1] and Chen et al. [2] who applied the sponge replica method to process powders of $\mathrm{CaO}-\mathrm{CaF}_{2}-\mathrm{P}_{2} \mathrm{O}_{5}-\mathrm{MgO}-\mathrm{ZnO}$ glass and $45 \mathrm{~S} 5$ Bioglass ${ }^{\circledR}$ $\left(45 \mathrm{SiO}_{2}-24.5 \mathrm{CaO}-24.5 \mathrm{Na}_{2} \mathrm{O}-6 \mathrm{P}_{2} \mathrm{O}_{5}\right.$ wt.\%), respectively. In both cases, the scaffolds exhibited a trabecular pore-strut architecture mimicking that of cancellous bone but the compressive strength was inadequate compared to the typical range of native tissue (2-12 MPa [3]). 45S5 glass has been considered an ideal material for producing bioactive scaffolds as it has a long story of clinical success, being approved by Food and Drug Administration (FDA) in 1993 and then implanted in various forms (fine particles, granules, putty) in more than 1.5 million patients worldwide to regenerate bone in orthopaedics and dentistry [4]. However, producing mechanically-strong scaffolds from $45 \mathrm{~S} 5$ Bioglass ${ }^{\circledR}$ is not an easy task as this glass has a narrow hot-working range and is prone to easily crystallize above $550^{\circ} \mathrm{C}[5-7]$. As a result, sintering becomes less efficient and leads to poorly densified porous glass-ceramic products that, furthermore, reduce the apatite-forming ability compared to the parent glass [8]. Strategies to improve the mechanical properties involved the change of the processing method and included both the production of $45 \mathrm{~S} 5 \mathrm{scaf}-$ folds with increasing porosity from the core to the outer shell by combining sponge replication and polyethylene burn-off method (compressive strength $0.7 \mathrm{MPa}$ vs. 0.3 MPa for conventional 45S5 Bioglass ${ }^{\circledR}$ foams) [9], or the use of rice husk as a sacrificial pore-generating agent (compressive strength 5-7 $\mathrm{MPa}$ ) which, however, led to poorlyinterconnected porous structures [10].

Alternatively, optimization of the processing parameters of the foam replica method (e.g. 45S5 glass particle size, sintering temperature) led to a significant incre-

O̊pen Access. (c) 2019 J. Barberi et al., published by De Gruyter. (cc) BY License 
ment of the compressive strength (2.5 MPa), which actually reached the lower threshold of trabecular bone range [11].

Impressive improvements were recently achieved by implementing additive manufacturing technologies (AMTs) in the field of biomedical ceramics and glasses [11]. For example, robocast grid-like 45S5 Bioglass ${ }^{\circledR}$-derived glass-ceramic scaffolds were reported to exhibit a compressive strength up to $10 \mathrm{MPa}$ [12]. This value can be further increased almost tenfold (above $80 \mathrm{MPa}$ ) when robocasting is applied to other bioactive glass compositions, such as $13-93\left(53 \mathrm{SiO}_{2}-20 \mathrm{CaO}-6 \mathrm{Na}_{2} \mathrm{O}-4 \mathrm{P}_{2} \mathrm{O}_{5}-5 \mathrm{MgO}-12 \mathrm{~K}_{2} \mathrm{O}\right.$ wt. $\left.\%\right)$, which has a better sinterability compared to $45 \mathrm{~S} 5$ [13] These strong scaffolds have been successfully proposed for the repair of high-load-bearing osseous defects in cortical bone sites [14].

AMTs have also shown great promise in the processing of mesoporous bioactive glasses (MBGs) [15], which possess a typical texture of ordered nanopores for use in drug delivery applications [16] and are therefore intrinsically very brittle. Wu et al. [17] used 3D printing to fabricate $\mathrm{SiO}_{2}-\mathrm{CaO}-\mathrm{P}_{2} \mathrm{O}_{5}$ MBG scaffolds (utilizing poly(vinyl alcohol) as a binder) and obtained macro-mesoporous hierarchical structures with compressive strength of $16 \mathrm{MPa}$, along with excellent apatite-forming ability and sustained drug release properties. 3D-printed Sr-doped MBG scaffolds were also shown to retain good mechanical strength ( $7 \mathrm{MPa}$ ) after being immersed for 1 week in simulated body fluids to mimic their evolution upon contact with body environment [18].

Recently, our research group exploited the great versatility of AMTs to fabricate silicate glass scaffolds with a gradient of porosity from the less porous core to the more porous outer shell [19]. Previous attempts addressed to fabricating pore-graded bioactive glass scaffolds were based on the use of sponge replica method. Bretcanu et al. [20] produced 45S5 Bioglass ${ }^{\circledR}$-derived scaffolds after thermally pre-forming a porous polymeric template that acquired a continuous porosity gradient. Vitale-Brovarone et al. [21] combined the foam replica technique with enameling to obtain 2-layer glass scaffolds mimicking the cancellouscortical bone system. Since AMTs allow a great control on internal geometry and pore arrangement of scaffolds, they are ideal methods to obtain 3D structures with a controlled variation in the inner porosity. In the present work, robocast pore-graded scaffolds were mechanically characterized by assessing their compressive strength, elastic modulus, fracture energy and Weibull modulus, which are all key features to take into account for a rational design of brittle porous biomaterials.

\section{Materials and methods}

\subsection{Bioactive glass scaffold fabrication}

Bioactive glass scaffolds were obtained by direct-ink writing of a self-sustaining ink through a fine nozzle into a grid-like shape. The starting glass used for scaffold manufacturing is called $47.5 \mathrm{~B}\left(47.5 \mathrm{SiO}_{2}-10 \mathrm{Na}_{2} \mathrm{O}-10 \mathrm{~K}_{2} \mathrm{O}-10 \mathrm{MgO}\right.$ 20CaO-2.5 $\mathrm{P}_{2} \mathrm{O}_{5}$ mol.\%) [22] and was considered suitable for making bone scaffolds thanks to its high bioactivity and great difference $\left(260^{\circ} \mathrm{C}\right)$ between glass transition temperature $\left(\mathrm{T}_{g}\right)$ and crystallization onset $\left(\mathrm{T}_{c}\right)$, known as sintering window, which allows good sintering of the glass while avoiding devitrification. The glass was obtained by melting the raw powder precursors $\left(\mathrm{SiO}_{2}, \mathrm{Na}_{2} \mathrm{CO}_{3}, \mathrm{~K}_{2} \mathrm{CO}_{3}\right.$, $\left(\mathrm{MgCO}_{3}\right)_{4} \cdot \mathrm{Mg}(\mathrm{OH})_{2} \cdot 5 \mathrm{H}_{2} \mathrm{O}, \mathrm{CaCO}_{3}$ and $\mathrm{Ca}_{3}\left(\mathrm{PO}_{4}\right)_{2}$, SigmaAldrich, St. Louis, MO, USA) up to $1500^{\circ} \mathrm{C}$ in a platinum crucible. The glass was cast in water to obtain a "frit" and then milled by a zirconia ball miller (Pulverisette 0, Frtisch, IdarOberstein, Germany). Glass powders with size below $32 \mu \mathrm{m}$ were obtained after sieving (stainless steel sieve, Giuliani Technologies Srl, Turin, Italy; mesh $32 \mu \mathrm{m})$. The ink was prepared by careful manual mixing of a polymeric binder solution (Pluronic F-127, 27.5 wt.\%) with glass particles in a plastic pot, in order to obtain a homogeneous and as much as possible air-free ink containing $35 \mathrm{vol} . \%$ of glass. A vortex mixer was used during the process (Vibrofix VF1 electronic, Ika-Werke, Staufen im Breisgau, Germany) (2500 rpm). Ink viscosity and density were not assessed in this work; rheological measurements will deserve to be carried in the future in order to further improve the reproducibility of the printing process and allow its easy scalability.

A pressure-controlled 3D printer from nScrypt was used (3Dn-Tabletop, nScrypt Inc., Orlando, FL, USA) to produce the scaffolds. This machine features a printing head that can move vertically (accuracy of $5 \mu \mathrm{m}$ ), while the displacement on the $x-y$ plane is achieved by movement of the printing plate (10 $\mu \mathrm{m}$ precision) [23]. The robocasting of the scaffolds was obtained by extruding the ink through a 410- $\mu \mathrm{m}$ diameter nozzle (Nordson EDF Optimum ${ }^{\circledR}$ SmoothFlow ${ }^{\mathrm{TM}}$, Nordsont Corporation, Westlake, Ohio, USA) onto acetate sheet (Colour Copier and Laser Transparecny OHP Film, Folex AG, Seewen, Switzerland). These printing substrates were chosen thanks to their flatness and the easy detachment of the dried scaffolds from their surfaces. Printing process was controlled through the factory-provided software (MachineTools 3.0, $\mathrm{nScrypt)}$, which allowed programming the nozzle raster pattern and the printing parameters (printing speed 2 $\mathrm{mm} / \mathrm{s}$, printing pressure 1.24-1.51 bar). The scaffolds were 
built by superimposing 20 identical layers, each of which was tilted by $90^{\circ}$ with respect to the underlying one. Each layer was made by 16 straight lines, long $8.91 \mathrm{~mm}$. The outer six from each side are spaced by $0.636 \mathrm{~mm}$, the inner lines by $0.51 \mathrm{~mm}$ : this was made in order to obtain pore-graded cuboid-shaped scaffolds, with a denser core (smaller pore dimensions) and a more porous outer layer. The robocast scaffolds were left drying for $48 \mathrm{~h}$ in air and then underwent a multistep consolidation process, in order to complete the removal of the polymeric binder and to sinter the glass particles. They were heated up to $600^{\circ} \mathrm{C}$ with a heating rate of $1^{\circ} \mathrm{C} / \mathrm{min}$. During the thermal treatment, the debinding was obtained by holding the samples for $30 \mathrm{~min}$ at 200,400 and $500^{\circ} \mathrm{C}$. The final sintering stage was achieved at $600^{\circ} \mathrm{C}$ for $1 \mathrm{~h}$. More precise and complete details about the fabrication process are published elsewhere [19].

\subsection{Morphological and structural characterization}

Porous scaffolds were investigated from morphological and microstructural viewpoints. Scanning electron microscopy (SEM) images were acquired (JCM-6000Plus, JEOL, Tokyo, Japan) in order to assess the outcome of the printing and sintering processes in terms of size of the structural features and particle consolidation. The samples were sputter-coated with chromium before undergoing SEM analysis.

The effect of the sintering temperature on the 47.5B scaffold microstructure was assessed by X-ray diffraction technique (XRD) (X'Pert Pro PW3040/60 diffractometer, PANalytical, Eindhoven, Netherlands). The analysis was performed varying the $2 \theta$ angle from 20 to $80^{\circ}$, the voltage was set to $40 \mathrm{kV}$ and the filament current to $30 \mathrm{~mA}$. Bragg-Brentano camera geometry was used, including $\mathrm{Cu}$ $\mathrm{K} \alpha$ incident radiation $(\lambda=0.15405 \mathrm{~nm})$. Data were acquired fixing the step counting time at $1 \mathrm{~s}$ and the step size at $0.02^{\circ}$. The scaffold was ground into powders prior to XRD investigation.

The total porosity P (vol.\%) of the scaffolds was assessed in quintuplicate by density measurements through the calculation of mass-to-volume ratio ( $\rho$ : apparent density; $\rho_{0}$ : bulk density):

$$
P=\left(1-\frac{\rho}{\rho_{0}}\right) \times 100
$$

\subsection{Mechanical testing}

Key aspects of scaffold mechanical properties required for bone-repair application, especially in load-bearing sites, were extensively characterized in this work. Twenty samples were mechanically tested under compressive loads (MTS Criterion, Model 43, MTS, Minnesota, USA; cell load $5 \mathrm{kN}$; cross-head speed $1 \mathrm{~mm} / \mathrm{min}$ ). The compressive strength $\sigma_{c}(\mathrm{MPa})$ was calculated as the ratio between the maximal load observed $\mathrm{L}_{M}(\mathrm{~N})$ and the resistant crosssection $\mathrm{A}_{r}\left(\mathrm{~mm}^{2}\right)$, which was measured for each sample by using callipers:

$$
\sigma_{c}=\frac{L_{M}}{A_{r}}
$$

The Young's modulus E (MPa) was determined from the linear region of the stress-strain response.

Fracture energy per unit volume $\mathrm{E}_{V}\left(\mathrm{~kJ} / \mathrm{m}^{3}\right)$, intended as the energy necessary to deform the scaffold specimen from the unloaded condition to the strain corresponding to the failure point $\left(\epsilon_{f}\right)$, was obtained calculating the area under the stress-strain curve until the breaking point [24]:

$$
E_{V}=\int_{0}^{\epsilon_{f}} \sigma(\epsilon) d \epsilon
$$

The function $\sigma(\epsilon)$ is represented by the stress-strain curves; the limits of the integral are: initial condition $\sigma(0)=0$; final condition $\sigma\left(\epsilon_{f}\right)=\sigma_{c}$ (from Equation (2)).

The three mechanical parameters mentioned above $\left(\sigma_{c}, \mathrm{E}, \mathrm{E}_{V}\right)$ were expressed as mean \pm standard deviation, resulting from the calculations on 20 tested specimens.

The Weibull modulus (m) was calculated referring to the ASTM C1239-07 standard [25]. Experimental data were fitted by the equation:

$$
\begin{aligned}
\ln \left(\ln \left(\frac{1}{1-P_{f}}\right)\right) & =m \ln \left(\frac{\sigma}{\sigma_{0}}\right) \\
& =m \ln (\sigma)-m \ln \left(\sigma_{0}\right)
\end{aligned}
$$

where $\mathrm{P}_{f}$ is the probability of failure at a given stress $\sigma$ and is calculated as $P_{f}=\frac{j-0.5}{n}$ (n: total number of samples tested; j: specimen rank in ascending order of failure stress); $\sigma_{0}$ is the Weibull scale factor, calculated using the intercept of the fitting line and the $m$ coefficient.

\section{Results and discussion}

The highly bioactive glass 47.5B [22] was chosen for the fabrication of 3D-printed scaffolds for bone repair application. The robocasting process was optimized to obtain fully 


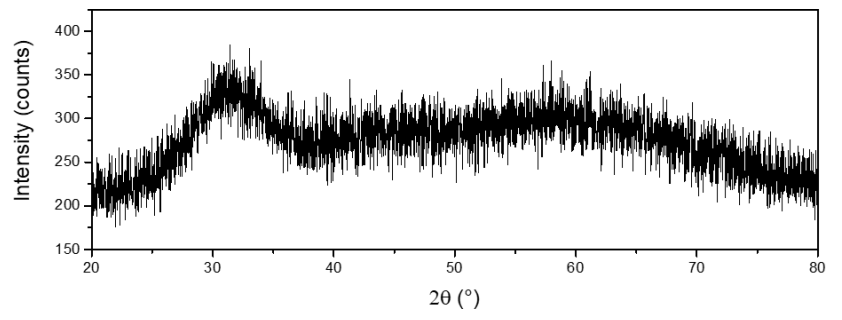

Figure 1: XRD pattern of crushed $47.5 \mathrm{~B}$ scaffold sintered at $600^{\circ} \mathrm{C}$

amorphous structures with suitable pore size to facilitate bone ingrowth. XRD analysis performed on sintered scaffolds confirmed that the thermal treatment at $600^{\circ} \mathrm{C}$ for $1 \mathrm{~h}$ was a suitable process for avoiding devitrification. Figure 1 shows the typical amorphous halo of silica-based glasses in the $2 \theta$-range of 25 to $40^{\circ}$ without any diffraction peaks This result is in accordance with previous findings [26].

Morphological observations were carried out to assess the geometrical features of scaffolds and to evaluate the consolidation of glass powders. Figures $2 \mathrm{a}$ and $2 \mathrm{~b}$ show that a very regular structure was obtained both in the asprinted scaffold and after sintering. The architecture of the $3 \mathrm{D}$ structure is very well maintained after thermal treatment, without undergoing deformation of the filaments but just normal shrinkage. The height of pores was $248 \pm 17$ $\mu \mathrm{m}$, while the pore width ranged from $213 \pm 24 \mu \mathrm{m}$ for the larger pores to $119 \pm 15 \mu \mathrm{m}$ in the center of the scaffolds. These values lie in the typical range recommended for bone tissue engineering scaffolds, so that the pore walls can potentially be colonized by cells and healthy bone tissue and vascularized by newly-formed blood vessels [27] The high-magnification image reported in Figure $2 \mathrm{c}$ allows observing well-consolidated glass powders in the scaffold rods: sintering necks are visible and single particles are hardly distinguishable. The total porosity of the scaffolds was $49.1 \pm 5.5$ vol. $\%$, which is very close to fulfil the minimum porosity requirement needed for bone scaffolds (50 vol.\%) [28].

An example of stress-strain curve obtained during the crushing test of the 47.5B glass scaffolds is reported in Figure 3. The plot exhibits a multi-peak profile, which is typical of brittle cellular materials, like ceramics and glasses [29]. This suggests that sequential fracture events take place during the compression, which actually generated the multiple peaks that can be seen in the curve. The curve has a positive slope up to a first peak, when the weaker (i.e. more defective) rods begin to crack, thus causing an apparent stress drop (negative slope). However, the scaffolds were still able to withstand higher loads and therefore the stress rises again. The repetition of this behaviour produces a jagged profile of the stress-curve while
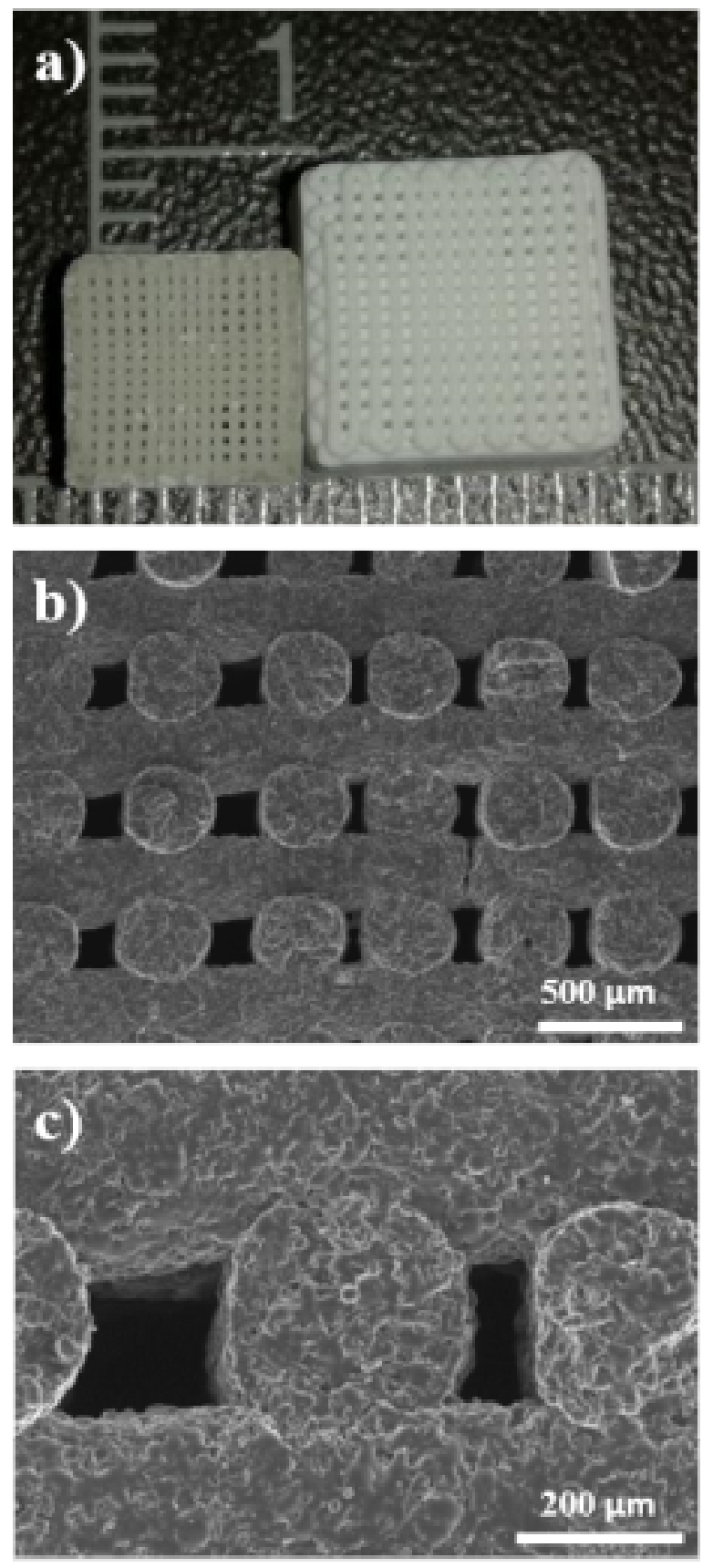

Figure 2: Investigation of the scaffold morphology: a) comparison of as-printed (right) and sintered (left) scaffolds (scale unit: $\mathrm{cm}$ ); b) SEM image of a cross-section, where the porosity gradient and the regular structure are well visible; 3 ) detail of glass struts and pores in the scaffold

the progressive cracking of scaffold struts occurs; when also the stronger rods are fractured, the curve has an ultimate negative slope. It is worth underlining that, from a qualitative viewpoint, these curves are analogous to those reported in previous studies for bioactive glass and ceramic scaffolds having a foam-like architecture [2, 30-32]; 


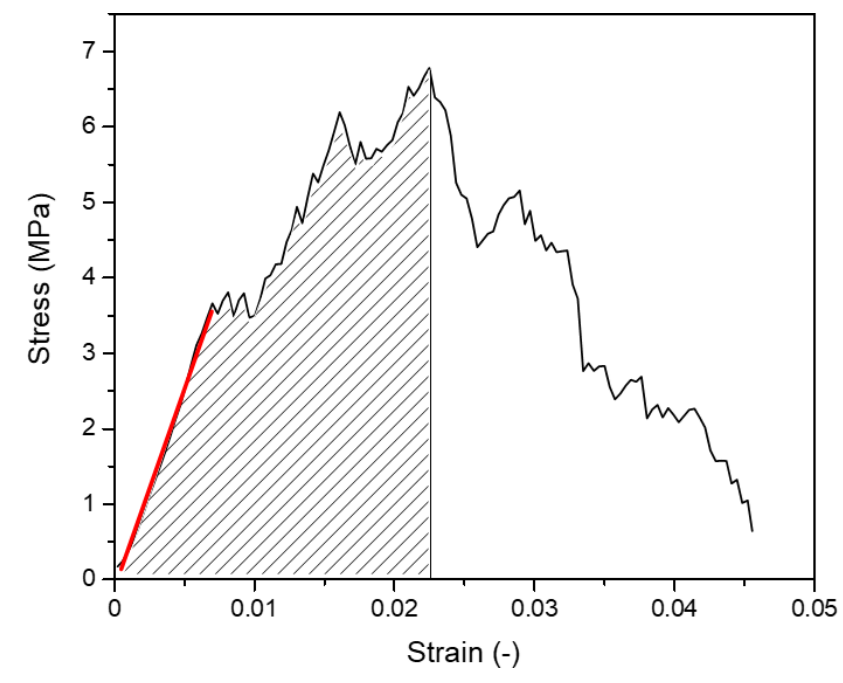

Figure 3: Stress-strain curve of 47.5B graded scaffold. The dashed area is the one accounted for the evaluation of fracture energy and the red line is the fitting used for calculating the Young's modulus.

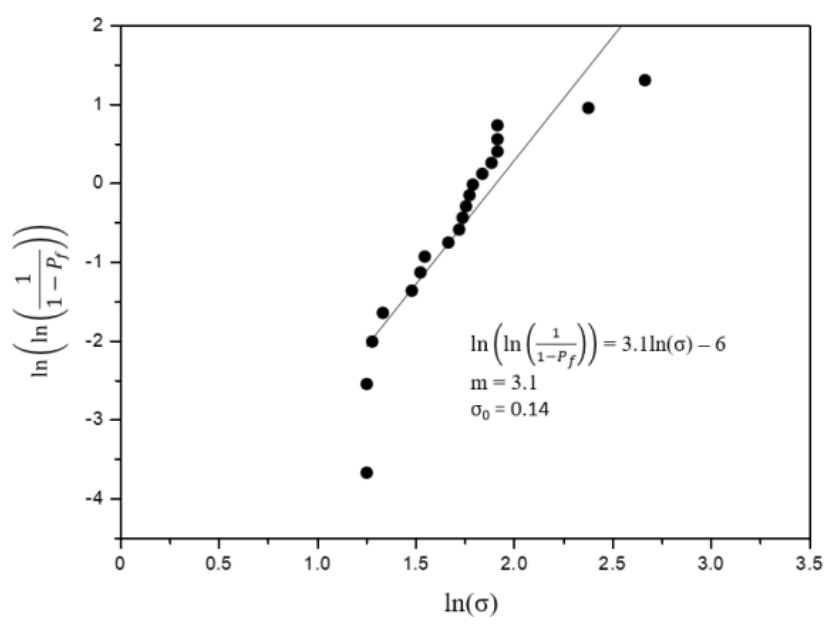

Figure 4: Weibull plot of the experimental data and theoretical interpolation. Fitting equation, Weibull modulus (m) and scale factor $\left(\sigma_{0}\right)$ are also reported.

this suggests that the 3D organization and spatial arrangement of macropores play a minor role in the mechanism of fracture in highly-porous brittle scaffolds.

The scaffold compressive strength was $6.1 \pm 2.6 \mathrm{MPa}$, matching the standard reference range (2-12 MPa [3]) considered for the human trabecular bone. These values are also comparable to those reported for 45S5 Bioglass ${ }^{\circledR}$ scaffolds produced by the same method (robocasting) and having similar porosity [12, 33]. The elastic modulus, $343 \pm 145$ $\mathrm{MPa}$, is within the range assessed for cancellous bone (50$500 \mathrm{MPa}$ [34]); this is an important achievement as one of the major reasons leading to postoperative implant failure is the stiffness mismatch between implanted biomaterial and surrounding bone.
The fracture energy of the scaffolds was $93 \pm 59 \mathrm{~kJ} / \mathrm{m}^{3}$; this parameter is seldom assessed in the literature for glass-derived scaffolds and the existing data are quite disperse, thus making a reliable comparison difficult to perform. It was reported that phosphate glass foams achieved a fracture energy of about $20 \mathrm{~kJ} / \mathrm{m}^{3}$ [35], and this value could be increased to $150 \mathrm{~kJ} / \mathrm{m}^{3}$ if the same material was processed by the polyethylene burn-off method [36]. Significantly higher values were obtained by Baino and VitaleBrovarone $\left(544 \mathrm{~kJ} / \mathrm{m}^{3}\right)$, who used sponge replication to produce $\mathrm{SiO}_{2}-\mathrm{CaO}-\mathrm{Na}_{2} \mathrm{O}-\mathrm{Al}_{2} \mathrm{O}_{3}$-based glass-ceramic scaffolds [37]. To the best of the authors' knowledge, no data have been reported on the fracture energy of robocast glass scaffolds so far.

The Weibull modulus is a key mechanical parameter that is often evaluated in the industrial practice; however, there is a paucity of studies dealing with its assessment in biomaterials science. A possible explanation is perhaps the need for a large number of samples, with associated costs, experimental time and reproducibility issues which may be difficult to overcome on a Lab-scale. The Weibull plot reported in Figure 4 shows an approximately linear trend over most of the stress range $\left(\mathrm{R}^{2}=\right.$ 0.79). Although some deviations from linearity can be observed at low and high stress values, this behaviour is commonly found in such type of tests, and can be therefore considered acceptable. Interpolation of experimental data yields a Weibull modulus $\mathrm{m}=3.1$ and a Weibull scale parameter $\sigma_{0}=0.14$, determined by knowing $\mathrm{m}$ and the intercept of the linear fit to the experimental data $(-6)$. The Weibull modulus provides a quantification of the scaffold mechanical reliability. Surface and internal flaws (e.g. micro-cracks and pores) strongly affect the mechanical performance of glasses and ceramics: therefore, the Weibull modulus is used to evaluate the probability of failure of brittle materials under a given stress. In this work, the Weibull modulus of 47.5B glass scaffolds is assessed for the first time; hence, a comparison with similar data from the literature is possible just considering other bioactive materials. Looking at the available publications, the Weibull modulus of bioactive porous ceramic and glass scaffolds is generally above 3. For example, the m-value of solid-freeform-fabricated porous hydroxyapatite, $\beta$-TCP and calcium polyphosphates scaffolds was reported to be in the range of 3 to 9 if tested in compression [38-40]. The Weibull modulus of the robocast $47.5 \mathrm{~B}$ glass scaffolds produced in this work lies in this range, although being very close to the lower limit. It is interesting to highlight that, even if the distribution of the strength values is quite broad, ranging from 3.8 to $14.4 \mathrm{MPa}$, none of the scaffolds showed a compressive strength lower than the minimum 
value that is typically considered for cancellous bone (2 MPa [3]).

Higher values of $\mathrm{m}$ were reported elsewhere on other glass compositions. The Weibull moduli of glassceramic foams produced from $\mathrm{SiO}_{2}-\mathrm{CaO}-\mathrm{Na}_{2} \mathrm{O}-\mathrm{Al}_{2} \mathrm{O}_{3}$ (SCNA) glass [37] and 45S5 Bioglass ${ }^{\circledR}$ powders [41] were found to be 4 and 6 , respectively.

It is worth underlining that the sintering temperature used in this work to consolidate the 47.5B scaffolds was relatively low, because the major scope of the work was to avoid crystallization: in this way, the good bioactivity of the material can be preserved, as illustrated in detail in [19]. As a result, the degree of densification of scaffold rods was not exceptionally high and a large number of residual inter-particle pores persisted in the sintered glass matrix. The presence of pores has a dramatic effect on the mechanical properties, which tend to decrease as the pores (defects) can act as crack initiator. Therefore, the Weibull modulus of 47.5B is negatively affected by two separate factors. One is the low densification achieved during the sintering process, which leaves a lot of defects between single particles. The second is related to the manufacturing process, especially to the air removal step during the ink fabrication. If air bubbles remain entrapped within the ink, they will create large defects inside the struts that cannot be eliminated even by pushing the sintering process to limit [42]. These bubbles are randomly distributed inside the ink and, accordingly, inside the scaffolds. The Weibull modulus, and the repeatability of the fabrication process, can be improved by optimizing the air bubble removal from the ink. Different methods have been proposed in the literature as more effective alternatives to the manual, including the use of a planetary centrifugal mixer [43] or much more complex protocols that involve the use of sonication [44].

Furthermore, Liu et al. [45] showed that the Weibull modulus of robocast 13-93 glass scaffolds can be increased to 12 if the extruded filament is deposited on an alumina substrate immersed in a reservoir of lamp oil: in this way, it was easier to control the drying rate and reduce the risk of strut cracking.

Further studies addressed to the optimization of the fabrication process, with special focus on air bubble removal and sintering, will deserve to be carried out to achieve better mechanical results and a lower dispersion of experimental data (i.e. a higher reproducibility of the samples).

\section{Conclusions}

In the present work, robocast silicate glass scaffolds with porosity gradient were extensively characterized regarding key mechanical features for bone repair application in load-bearing sites. Compressive strength, Young's modulus and fracture energy need to be investigated and tailored for the correct design of bone substitute materials, while the Weibull modulus is more concerned with the reliability of the materials and fabrication method. 3Dprinted scaffolds exhibited compressive strength and elastic modulus that matched quite well the typical values of the human cancellous bone. These results are promising, since the scaffolds obtained in this way might ensure a correct load transfer with the surrounding tissue. Fracture energy is a harder parameter to comment, since very few and disperse studies are present in the literature. Nevertheless, the values obtained in this work are comparable with pre-existing data on bioactive glass foams. At last, Weibull modulus was negatively affected by the Lab-scale and fully manual ink preparation protocol, which resulted into several air bubble-derived defects within the scaffold struts. Even though, the m-value lies in the range reported in the literature for bioceramic scaffolds. In conclusion, robocasting is a promising method for the fabrication of scaffolds having suitable mechanical properties for application as load-bearing bone substitutes; future research work should aim at improving the reliability of the fabrication process.

Ethical approval: The conducted research is not related to either human or animals use.

Conflict of Interests: The authors declare no conflict of interest regarding the publication of this paper.

\section{References}

[1] Park Y.S., Kim K.N., Kim K.M., Choi S.H., Kim C.K., Legeros R.Z., et al., Feasibility of three-dimensional macroporous scaffold using calcium phosphate glass and polyurethane sponge, J. Mater. Sci., 2006, 41, 4357-64.

[2] Chen Q.Z., Thompson I.D., Boccaccini A.R., $45 \mathrm{~S} 5$ Bioglasss ${ }^{\circledR}$. derived glass-ceramic scaffolds for bone tissue engineering, Biomaterials, 2006, 27, 2414-25.

[3] Hench L.L., Bioceramics: from concept to clinic, J. Am. Ceram. Soc., 1991, 74, 1487-510.

[4] Jones J.R., Brauer D.S., Hupa L., Greenspan D.C., Bioglass and bioactive glasses and their impact on healthcare, Int. J. Appl. Glass Sci., 2016, 7, 423-34. 
[5] Massera J., Fagerlund S., Hupa L., Hupa M., Crystallization mechanism of the bioactive glasses, $45 \mathrm{~S} 5$ and S53P4, J. Am. Ceram. Soc., 2012, 95, 607-13.

[6] Golovchak R., Thapar P., Ingram A., Savytskii D., Jain H., Influence of phase separation on the devitrification of $45 \mathrm{~S} 5$ bioglass, Acta Biomater., 2014, 10, 4878-86.

[7] Baino F., Fiume E., Quantifying the effect of particle size on the crystallization of 45S5 bioactive glass, Mater. Lett., 2018, 224, 54-8.

[8] Peitl O.F., Latorre G.P., Hench L.L., Effect of crystallization on apatite-layer formation of bioactive glass 45S5, J. Biomed. Mater. Res., 1996, 30, 509-14.

[9] Bellucci D., Chiellini F., Ciardelli G., Gazzarri M., Gentile P., Sola A., et al., Processing and characterization of innovative scaffolds for bone tissue engineering, J. Mater. Sci. Mater. Med., 2012, 23, 1397-409.

[10] Wu S.C., Hsu H.C., Hsiao S.H., Ho W.F., Preparation of porous 45S5 Bioglass ${ }^{\circledR}$-derived glass-ceramic scaffolds by using rice husk as a porogen additive, J. Mater. Sci. Mater. Med., 2009, 20, 1229-36.

[11] Baino F., Ferraris M., Bretcanu O., Verné E., Vitale-Brovarone C., Optimization of composition, structure and mechanical strength of bioactive 3-D glass-ceramic scaffolds for bone substitution, J. Biomater. Appl., 2013, 27, 872-90.

[12] Motealleh A., Eqtesadi S., Civantos A., Pajares A., Miranda P., Robocast $45 \mathrm{~S} 5$ bioglass scaffolds: in vitro behavior, J. Mater. Sci., 2017, 52, 9179-91.

[13] Fu Q., Saiz E., Tomsia A.P., Direct ink writing of highly porous and strong glass scaffolds for load-bearing bone defects repair and regeneration, Acta Biomater., 2011, 7, 3547-54.

[14] Rahaman M.N., Xiao W., Fu Q., Huang W., Review - Bioactive glass implants for potential application in structural bone repair, Biomed. Glasses, 2017, 3, 56-66.

[15] Ma H., Feng C., Chang J., Wu C., 3D-printed bioceramic scaffolds: From bone tissue engineering to tumor therapy, Acta Biomater., 2018, 79, 37-59.

[16] Wu C., Chang J., Multifunctional mesoporous bioactive glasses for effective delivery of therapeutic ions and drug/growth factors, J. Controll. Rel., 2014, 193 ,282-95.

[17] Wu C., Luo Y., Cuniberti G., Xiao Y., Gelinsky M., Threedimensional printing of hierarchical and tough mesoporous bioactive glass scaffolds with a controllable pore architecture, excellent mechanical strength and mineralization ability, Acta Biomater, 2011, 7, 2644-50.

[18] Zhang J., Zhao S., Zhu Y., Huang Y., Zhu M., Tao C., et al., Threedimensional printing of strontium-containing mesoporous bioactive glass scaffolds for bone regeneration, Acta Biomater., 2014, 10, 2269-81.

[19] Barberi J., Baino F., Fiume E., Orlygsson G., Nommeots-Nomm A., Massera J., et al., Robocasting of SiO2-based bioactive glass scaffolds with porosity gradient for bone regeneration and loadbearing application, Materials, 2019, 12, 2691.

[20] Bretcanu O., Samaille C., Boccaccini A.R., Simple methods to fabricate Bioglass ${ }^{\circledR}$-derived glass-ceramic scaffolds exhibiting porosity gradient, J. Mater. Sci., 2008, 43, 4127-34.

[21] Vitale-Brovarone C., Baino F., Verné E., Feasibility and tailoring of bioactive glass-ceramic scaffolds with gradient of porosity for bone grafting, J. Biomater. Appl., 2010, 24, 693-712.

[22] Verné E., Bretcanu O., Balagna C., Bianchi C.L., Cannas M., Gatti S., et al., Early stage reactivity and in vitro behavior of silica- based bioactive glasses and glass-ceramics, J. Mater. Sci. Mater. Med., 2009, 20, 75-87.

[23] "nScrypt", December 2017, https://www.nscrypt.com/ wpcontent/uploads/2018/11/2018-3Dn-Brochure.pdf

[24] Kenesei P., Kádár C., Rajkovits Z., Lendvai J., The influence of cell-size distribution on the plastic deformation in metal foams, Scripta Mater., 2004, 50, 295-300.

[25] ASTM C1239-13, Standard Practice for Reporting Uniaxial Strength Data and Estimating Weibull Distribution Parameters for Advanced Ceramics, 2018.

[26] Baino F., Barberi J., Fiume E., Orlygsson G., Massera J., Verné E., Robocasting of bioactive SiO2-P2O5-CaO-MgO-Na2O-K2O glass scaffolds, J. Healthcare Eng., 2019, 2019, 5153136.

[27] Gerhardt L.C., Boccaccini A.R., Bioactive glass and glass-ceramic scaffolds for bone tissue engineering, Materials, 2010, 3, 3867910.

[28] Karageorgiou V., Kaplan D., Porosity of 3D biomaterial scaffolds and osteogenesis, Biomaterials, 2005, 26, 5474-91.

[29] Gibson L.J., Modelling the mechanical behavior of cellular materials, Mater. Sci. Eng. A, 1989, 110, 1-36.

[30] Vitale-Brovarone C., Baino F., Verné E., High strength bioactive glass-ceramic scaffolds for bone regeneration, J. Mater. Sci. Mater. Med., 2009, 20, 643-53.

[31] Vitale-Brovarone C., Baino F., Bretcanu O., Verné E., Foam-like scaffolds for bone tissue engineering based on a novel couple of silicate-phosphate specular glasses: Synthesis and properties, J. Mater. Sci. Mater. Med., 2009, 20, 2197-205.

[32] Poologasundarampillai G., Lee P.D., Lam C., Kourkouta A.M., Jones J.R., Compressive strength of bioactive sol-gel glass foam scaffolds, Int. J. Appl. Glass Sci., 2016, 7, 229-37.

[33] Eqtesadi S., Motealleh A., Miranda P., Pajares A., Lemos A., Ferreira J.M.F., Robocasting of $45 \mathrm{~S} 5$ bioactive glass scaffolds for bone tissue engineering, J. Eur. Ceram. Soc., 2014, 34, 107-18.

[34] Thompson I.D., Hench L.L., Mechanical properties of bioactive glasses, glass-ceramics and composites, Proc. Inst. Mech. Eng. H J. Eng. Med., 1998, 212, 127-36.

[35] Vitale-Brovarone C., Ciapetti G., Leonardi E., Baldini N., Bretcanu O., Verné E., et al., Resorbable glass-ceramic phosphate-based scaffolds for bone tissue engineering: synthesis, properties, and in vitro effects on human marrow stromal cells, J. Biomater. Appl., 2011, 26, 465-89.

[36] Bretcanu O., Baino F., Verné E., Vitale-Brovarone C., Novel resorbable glass-ceramic scaffolds for hard tissue engineering: From the parent phosphate glass to its bone-like macroporous derivatives, J. Biomater. Appl., 2014, 28, 1287-303.

[37] Baino F., Vitale-Brovarone C., Mechanical properties and reliability of glass-ceramic foam scaffolds for bone repair, Mater. Lett., 2014, 118, 27-30.

[38] Miranda P., Pajares A., Saiz E., Tomsia A.P., Guiberteau F., Mechanical properties of calcium phosphate scaffolds fabricated by robocasting, J. Biomed. Mater. Res. A, 2008, 85, 218-27.

[39] Martínez-Vázquez F.J., Perera F.H., Miranda P., Pajares A., Guiberteau F., Improving the compressive strength of bioceramic robocast scaffolds by polymer infiltration, Acta Biomater., 2010, 6, 4361-8.

[40] Shanjani Y., Hu Y., Pilliar R.M., Toyserkani E., Mechanical characteristics of solid-freeform-fabricated porous calcium polyphosphate structures with oriented stacked layers, Acta Biomater., 2011, 1788-96. 
[41] Baino F., Fiume E., Mechanical characterization of $45 \mathrm{~S} 5$ bioactive glass-derived scaffolds, Mater. Lett., 2019, 245, 14-7.

[42] Nommeots-Nomm A., Ligorio C., Bodey A.J., Cai B., Jones J.R., Lee P.D., et al., Four-dimensional imaging and quantification of viscous flow sintering within a 3D printed bioactive glass scaffold using synchrotron X-ray tomography, Mater. Today Adv., 2019, 2, 100011.

[43] Nommeots-Nomm A., Lee P.D., Jones J.R., Direct ink writing of highly bioactive glasses, J. Eur. Ceram. Soc., 2018, 38, 837-44.
[44] Franco J., Hunger P., Launey M.E., Tomsia A.P., Saiz E., Direct write assembly of calcium phosphate scaffolds using a water-based hydrogel, Acta Biomater., 2010, 6, 218-28.

[45] Liu X., Rahaman M.N., Hilmas G.E., Bal B.S., Mechanical properties of bioactive glass (13-93) scaffolds fabricated by robotic deposition for structural bone repair, Acta Biomater., 2013, 9 , 7025-34. 